\title{
Impact of attachment, temperament and parenting on human development
}

Yoo Rha Hong, MD, Jae Sun Park, MD

Department of Pediatrics, Kosin University College of Medicine, Busan, Korea
Received: 8 August, 2012, Accepted: 25 October, 2012

Corresponding author: Jae Sun Park, MD

Department of Pediatrics, Kosin University College of Medicine, 262 Gamcheon-ro, Seo-gu, Busan 602-702, Korea

Tel: +82-51-990-6230, Fax: +82-51-990-3005

E-mail: pjs@ns.kosinmed.or.kr

Copyright (C 2012 by The Korean Pediatric Society
The purpose of this review is to present the basic concepts of attachment theory and temperament traits and to discuss the integration of these concepts into parenting practices. Attachment is a basic human need for a close and intimate relationship between infants and their caregivers. Responsive and contingent parenting produces securely attached children who show more curiosity, selfreliance, and independence. Securely attached children also tend to become more resilient and competent adults. In contrast, those who do not experience a secure attachment with their caregivers may have difficulty getting along with others and be unable to develop a sense of confidence or trust in others. Children who are slow to adjust or are shy or irritable are likely to experience conflict with their parents and are likely to receive less parental acceptance or encouragement, which can make the children feel inadequate or unworthy. However, the influence of children's temperament or other attributes may be mitigated if parents adjust their caregiving behaviors to better fit the needs of the particular child. Reflecting on these arguments and our childhood relationships with our own parents can help us develop the skills needed to provide effective guidance and nurturance.

Key words: Attachment, Parenting, Temperament, Development, Child

This is an open-access article distributed under the terms of the Creative Commons Attribution Non-Commercial License (http://creativecommons.org/licenses/bync/3.0/) which permits unrestricted non-commercial use, distribution, and reproduction in any medium, provided the original work is properly cited.

\section{Introduction}

The birth of a child initiates a life-long process of mutual adaptation between the child and his or her caregivers and the broader social environment. Relationships and patterns of interactions formed during the early stages of life serve as a prototype for many interactions later in life and might have life-long effects ${ }^{1)}$. Young children do not have the language ability to express to their caregivers what they need, so children often communicate through their behavior. Parents are often unaware of their child's feelings or the mental representations of their emotions. Thus, attentive attunement to all aspects of a child is a very demanding task. Parents want their infants to grow up healthy and to develop behaviors that allow them to take charge of their own lives. Parents want to know how to provide the best parenting possible, especially when they do not want a mere repetition of their own individual family histories. A review of previous research findings will provide some guidelines to answer this question. 


\section{Bowlby's key ideas about infant-caregiver attachment}

According to John Bowlby's theory" of attachment development, a child is "attached" to someone when he or she is "strongly disposed to seek proximity to and contact with a specific figure and to do so in certain situations, notably when he is frightened, tired or ill." $\mathrm{He}$ noted the close attachment relationship between responsive caregivers (typically the mother, but not always) and infants from about 6 months to 2 years of age.

The emotionally charged connection between caregiver and child ensures that the two will remain in physical proximity, especially when the child is between 8 and 18 months of age. When the infant becomes more mobile, he will rely on the caregiver less often for proximity maintenance, although he does not abandon it altogether. Once the child experiences the security of this physical closeness, he will develop the courage to explore away from the caregiver. This fascinating paradox, the conversion from pursuing closeness to moving away from dependence, is the core of attachment theory. In other words, when a child is securely attached to his mother and the feeling of closeness is restored, the seeking of proximity and closeness recedes and the child turns to other interests, comfortably using the caregiver as a base of operations from which to explore.

\section{Ainsworth's research model for testing attachment quality}

Mary Ainsworth, a developmental psychologist who studied with Bowlby, developed a controlled laboratory situation called the "strange situation," so named because it is a novel experience for the child ${ }^{2}$. Ainsworth had mother and 12-month-old infant pairs play in a room with toys and observed the infant's reactions to several situations, including separation, for 20 minutes. First, would the infants use the mother as a secure base to explore the room and the new toys when the mother sits in the playroom, or would they cling to their mother and refuse to explore? Second, what would happen if the mother was told to leave the room briefly and a stranger entered? Would the child be distressed but then comforted, or would they remain distressed for the entire period the mother was gone? Third, what happened when the mother returned? Would the child be relieved, would they be indifferent, or would they be distressed?

From the children's responses to these situations, Ainsworth found that most infants had secure attachments. They played and explored comfortably when their mothers were present, became visibly upset when they left, and calmed quickly upon their return. Some infants, however, sought little contact with their mothers and were not distressed when they left. Ainsworth labeled these patterns avoidant attachment. Finally, some infants showed anxiety even when their mothers were near. Although they protested excessively when their mothers left, they were not particularly comforted when they returned, a pattern Ainsworth labeled ambivalent (anxiousambivalent, resistant) attachment. These three patterns are described according to the caregiver's style (Fig. 1). A fourth category, termed disorganized attachment, was subsequently identified by Main and Solomon and later added to Ainsworth's original tripartite classification ${ }^{3)}$ (Table 1).

\section{What makes the difference in attachment quality or style?}

Although Bowlby acknowledged that feeding may facilitate mother-infant proximity, attachment is not merely a function of feeding ${ }^{4}$. Harlow and Zimmermann's monkey study ${ }^{5}$ and Bowlby's observation ${ }^{1)}$ in orphanages suggest that infants need emotional support and contact in addition to food and shelter. Ainsworth et al. ${ }^{2)}$ also closely observed mothers and children in their homes and

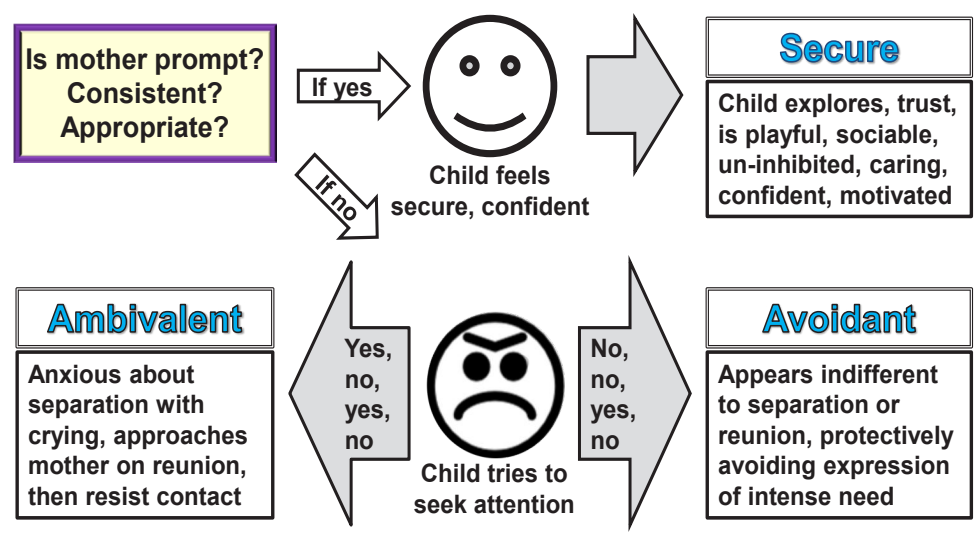

Fig. 1. Three patterns of attachment corresponding to Ainsworth's caregiving style. 
paid careful attention to each mother's style of responding to her infant's behaviors, such as feeding, crying, cuddling, eye contact, and smiling, before the infants" behavior was assessed in the "strange situation." Responsive mothers were mothers who provided physical care, emotional communication, and affection to their children in clear relation to their signals of need. The mother's reciprocal or contingent responses (reinforcement depending on the behavior of the child) by eye contact, cuddling, touching, or praise may reinforce the child's communicative attempts, such as babbling or laughing. Responsive mothers also gave their children enough "space" when they were playing, crawling, or otherwise exploring their environment independently. The critical aspect of responsive caregiving is that the mothers are aware of their children's needs and wants and respond to that information. The responsive caregiver "resonates" with the child's messages even though they are difficult for others to decipher at first.

Traditionally, most Korean mothers practiced what pediatrician William Sears calls "attachment parenting"(); they usually engaged in long-term breastfeeding, carried their infants in fabric slings on their backs while doing housework (babywearing), and cosleeping (an infant and mother sleeping side by side in the same room). This close proximity of the infant to her mother could provide an optimal environment for better interactions and attachment.

\section{Infant attachment styles and adult personality}

Longitudinal data using adult attachment interviews suggest that attachment insecurity does indeed serve as a risk factor for psychopathology ${ }^{7-11)}$. Insecurely attached children are likely to develop fewer social skills and have lower levels of communication skills. An insecurely attached child may frequently become anxious, even in benign circumstances. Chronic vigilance and anxiety will then increase the probability of a future anxiety disorder ${ }^{7}$. Anxiety is a very powerful stimulus of emotional distress that puts a person in a high arousal state (a state of hyper-responsiveness to sensory stimulation or excitability). Either too little arousal (lack of sensory input or boredom) or too much prolonged arousal is detrimental. Consequently, optimal performance cannot be attained because of an inability to maintain an appropriate level of arousal.

Indeed, the Adult Attachment Interview draws its validity from the high correspondence between the attachment classification of parents and their infants' classifications in the Strange Situation ${ }^{8)}$. Thus, "secure," "avoidant," "ambivalent (anxious-ambivalent, resistant)," and "disorganized" infants tend to have primary caregivers who are "autonomous," "dismissing," "preoccupied," and "unresolved," respectively, with respect to attachment ${ }^{12}$. Categories of attachment behaviors of infants in the strange situation and corresponding attachment categories among adults are proposed in several studies ${ }^{9,12)}$ (Table 1). Jang ${ }^{13)}$ observed exact agreement between infant category and corresponding adult category (maternal working model) in 11 out of the 20 dyads (55\%) she studied, and she argued that attachment styles can transmit over generations. Another study in South Korea by Jung ${ }^{14)}$ with 239 dyads of preschool children and their mothers confirmed that children's attachment patterns were related to their mothers' attachment patterns to their own mothers. Parental insecure attachment styles also have a crucial impact on the development of psychiatric manifestations in school-aged children. Yoo et al. ${ }^{15)}$ reported that parents who were judged to be preoccupied had children with more internalized symptoms than those who were judged to be secure, whereas dismissing/avoidant parents had children with higher scores on attention problems, and fearful/ avoidant parents had children with more externalized symptoms.

\section{Temperament traits of children}

The possibility that attachment security is partially influenced biologically in relation with temperament needs to be examined. Temperament can be described as a neurobiological element of the individual that differs from person to person in emotions, sociability,

Table 1. Types of Attachment in Infants in Strange Situation and Corresponding Adult Categories

\begin{tabular}{|c|c|c|c|c|}
\hline Attachment of infant & Secure & Avoidant & Ambivalent & Disorganized \\
\hline$\%$ of infants & $50-70$ & $10-20$ & $10-20$ & 5 \\
\hline Exploration of environment & + & + & - & $+/-$ \\
\hline Stranger anxiety & + & - & ++ & - \\
\hline Separation anxiety & + & - & ++ & $+/-$ \\
\hline Reunion behavior & Happy & Avoid contact & Seek \& reject & Afraid of carer \\
\hline Attachment of adult & Autonomous & Dismissing & Preoccupied & Unresolved \\
\hline Features & Comfortable, seek support & Keep distance from others & Fear of rejection & Confused, disoriented \\
\hline Images of self \& others & Positive self, positive other & Positive self, negative other & Negative self, positive other & Negative self, negative other \\
\hline
\end{tabular}

+, infant exhibited the anticipated behavior; -, infant did not exhibit the behavior; +/-, infant's behavior is inconsistent, sometimes present sometimes not; ++, infant exhibited the behavior very intensely. 
and self-control. Temperament is epigenetic, originating in genes but also affected by child-rearing practices. Although certain dopamine receptor D4 polymorphisms (a 48 base-pair repeat in exon 3 of DRD4) are associated with low neuronal reactivity, increased exploratory behavior, and novelty seeking ${ }^{16}$, such associations require replication studies before they can be viewed as causative. The concept of temperament can help parents understand and accept the characteristics of their children without feeling responsible for having caused them. Identifying children's temperaments may also allow for adjustment in parenting styles.

The New York Longitudinal Study was started in 1956 by Thomas and Chess ${ }^{17}$. This classic study of temperament traits in children followed 133 individuals from 84 families, predominantly educated families in New York, from 3 months of age to adulthood, and observed how well they fit in at school, with their friends, and at home. Results of the study revealed nine temperamental dimensions ${ }^{17,18)}$.

\section{Dimensions and broad types of temperament traits}

In addition to the nine dimensions, Thomas and $\mathrm{Chess}^{17)}$ also classified children's temperaments into three types. Approximately $40 \%$ of the children in the total sample were deemed to be "easy children" who are generally cheerful and adapt quickly to new foods and new people, $10 \%$ were "difficult children" who tend to be easily frustrated and contribute to negative social interactions, and 15\% were "fearful children" who have relatively low activity levels and tend to withdraw on their first exposure to new stimuli (Table 2). The remaining 35\% did not seem to be easily classified into one of these groups. There have been numerous other investigations to characterize the structure of temperament. Among them, the three dimensions of extraversion/surgency, negative affectivity, and effortful self-control forged by Rothbart and Bates ${ }^{19)}$, and two basic dimensions of uninhibited and inhibited, with intermediate phenotype by Kagan and Fox ${ }^{20)}$ are now most widely accepted (Table 2).

\section{Parenting and parenting styles}

Parents are children's first and foremost nurturers, teachers, guides, counselors, and protectors. Parents wonder what their children will be like when they grow up and want them to become the most capable adults they can be. However, parents differ on how they raise and interact with their children. Growing up with great parents is a great blessing in life, and the way a child is raised influences the kind of person he or she will become. As attachment styles seem to transfer over generations, so do parenting styles. From this context, it is a real success in life and realization of human potential if an individual who grew up in a disadvantaged or ill-treated family breaks the vicious cycle and practices positive parenting.

Children who misbehave often do so not out of malice, but out of ignorance, boredom, or frustration, and simply need to be taught, listened to, or redirected. A child who is ignored by his parents often misbehaves as a way to seek attention. When parents respond immediately to attention-seeking misbehaviors, such as temper tantrums or screaming, it inadvertently reinforces that behavior. Instead, rewarding the child's appropriate behaviors with praise and hugs can be more effective. It is important to catch them being good and to avoid expressing negative judgments or using incorrect labels that demean the child. What we believe about others or ourselves can become true due to a self-fulfilling prophecy because we tend to act in accordance with what we believe. Children develop their opinions about themselves by observing the way significant others respond to

Table 2. Types and Dimensions of Temperament of Children Studied by Researchers

\begin{tabular}{|c|c|c|}
\hline Types of children based on Thomas and Chess' dimensions ${ }^{18)}$ & Dimensions by Rothbart and Bates ${ }^{19)}$ & Dimensions by Kagan and Fox ${ }^{20)}$ \\
\hline Easy (flexible) child 40\% & Extraversion/surgency & Uninhibited 25-30\% \\
\hline $\begin{array}{l}\text { Regular "rhythm" with positive "mood," ease of "approach," } \\
\text { "adaptation" to novel stimuli with less irritation. }\end{array}$ & $\begin{array}{l}\text { Positive anticipation, approach, seek pleasure and } \\
\text { sensation with impulsivity. (Fit to Kagan's uninhibited) }\end{array}$ & $\begin{array}{l}\text { Sociable, extraverted, bold, outgoing } \\
\text { behaviors. }\end{array}$ \\
\hline Difficult (feisty) child 10\% & Negative affectivity & Inhibited 15-20\% \\
\hline $\begin{array}{l}\text { Sleep irregularly, withdraw, slow to adapt, irritated easily } \\
\text { (low "sensitivity threshold"), easily upset (high "intensity of } \\
\text { reaction"), easily diverted (high "distractibility"). }\end{array}$ & $\begin{array}{l}\text { Fear, anger, sadness, easily crying and frustrated } \\
\text { with social discomfort. (Similar to Kagan's inhibited) }\end{array}$ & $\begin{array}{l}\text { Shy, subdued, timid and cautious to the } \\
\text { unfamiliar peers or adults, beginning } \\
\text { about } 7 \text { to } 9 \text { months of age. }\end{array}$ \\
\hline Slow to warm up (fearful) child 15\% & Effortful self-control & Intermediate phenotype* \\
\hline $\begin{array}{l}\text { Low "activity level," withdraw, adapt cautiously, and } \\
\text { somewhat negative in mood with low intensity of mood } \\
\text { expression. }\end{array}$ & $\begin{array}{l}\text { Focusing their attention to execute a more adaptive } \\
\text { response and inhibitory control. Child low on self- } \\
\text { control is easily agitated. }\end{array}$ & $\begin{array}{l}\text { With experience, some inhibited child- } \\
\text { ren moved into the intermediate, as } \\
\text { they showed less fear at } 7 \text { years of age. }\end{array}$ \\
\hline
\end{tabular}

Percents represent the proportions of children belonging to the category of the classification system.

The terms enclosed with quotation marks are Thomas and Chess' temperament dimensions ${ }^{18}$.

*The term is not a specific dimension, but used to describe some children whose behavioral patterns diverged somewhat at later years probably by environmental factors. 
and communicate with them. A parent's feedback or opinions about them are social mirrors and are used to form self-images and selfjudgments.

Baumrind $^{21)}$ defined three categories of principal parenting styles. The categories, which were later extended to include indifferent or negligent parents, were as follows: authoritative (demanding and responsive to child with respectful attitude), authoritarian (demanding but not responsive, "do-as-I-say" style), permissive or indulgent (more responsive than demanding), and indifferent or neglecting (neither demanding nor responsive). Authoritative parenting is, by far, the most effective parenting styles because it promotes a child's ability to withstand potentially negative influences, including life stress and exposure to antisocial peers. Authoritarian parents are likely to produce anxious youth with low self-esteem, lack of spontaneity, and lack of intellectual curiosity ${ }^{22}$ (Fig. 2).

\section{Adequacy of parental responses to temperament (goodness-of-fit)}

Parenting is a reciprocal process in which the parent influences the child's development, and in return, the child influences the parent. The influence of temperament and other attributes of children may be mitigated or negligible as long as caregivers modify their behavior to fit the needs of the children ${ }^{23}$. However, when a mother's capacity to do so is limited by her own personality or stressful conditions, then infants with a difficult temperament or problem behaviors are at risk for developing attachment insecurity. Studies have shown that most securely attached infants develop distinctly different attachment bonds with each parent and their various caregivers ${ }^{24)}$. This suggests that parents can modulate their children's temperament by influencing their children's environment. For instance, Chess et al. ${ }^{18)}$ have recognized that behaviors that lead to a child being

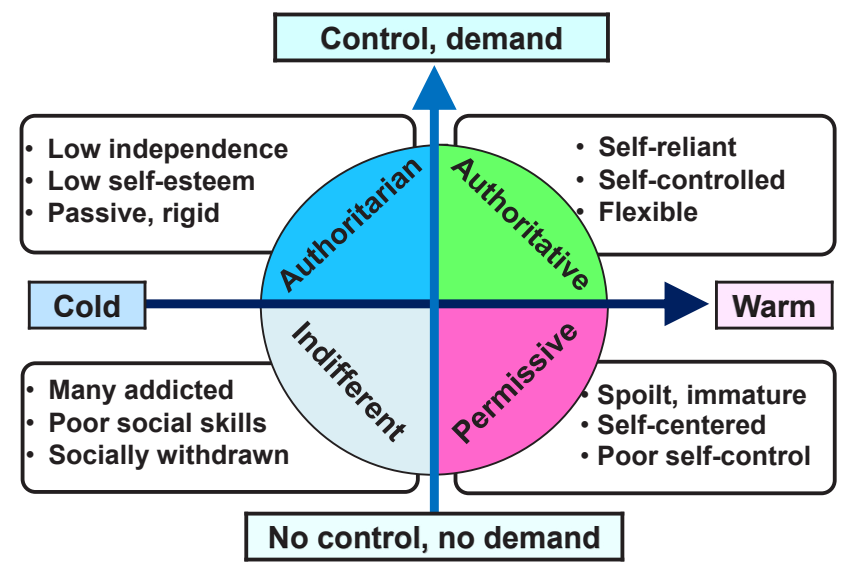

Fig. 2. Children's characteristics produced from different parenting styles. classified as "easy" or "difficult" can vary depending on parental and cultural values, attitudes, and practices. Hence, they emphasize that interaction should be considered in terms of "goodness-of-fit," which is the compatibility of a person's temperament with their family, school, and community. Any temperament trait may not be inherently problematic; rather, it is the interaction that determines the "acceptability" of that trait.

"Reflective parenting" is a theory of parenting derived from Fonagy et al.'s concept ${ }^{25)}$ of "reflective functioning," which refers to the human capacity to understand the behavior of the self and others in light of underlying mental states and intentions. Mothers in a high-stress or overcrowded environment, or who are deprived of employment security, would be more likely to have securely attached infants if they respond to the children's motivations rather than their actions.

\section{Conclusions}

From several core ideas of early life experiences, we can discern valuable insights into parenting practices. Sensitive and responsive care from parents is vital for the optimal growth and development of each child. Children who are rarely spoken to, who are left to cry themselves out, who have little opportunity to explore their environment, or who experience frequent anger or boredom cannot fully develop their potential and stable personalities, despite their normal genetic endowment.

\section{References}

1. Bowlby J. Attachment and loss. Vol 1, Attachment. London: The Hogarth Press and the Institute of Psycho-Analysis, 1969:1-401.

2. Ainsworth MD, Blehar MC, Waters E, Wall S. Patterns of attachment: a psychological study of the strange situation. Hillsdale: Lawrence Erlbaum Associates, 1978:116-36.

3. Main M, Solomon J. Procedures for identifying infants as disorganized/ disoriented during the Ainsworth Strange Situation. In: Greenberg MT, Cicchetti D, Cummings EM, editors. Attachment in the preschool years: theory, research and intervention. Chicago: University of Chicago Press, 1990:121-60.

4. Bowlby J. The nature of the child's tie to his mother. Int J Psychoanal 1958;39:350-73.

5. Harlow HF, Zimmermann RR. Affectional responses in the infant monkey; orphaned baby monkeys develop a strong and persistent attachment to inanimate surrogate mothers. Science 1959;130:421-32.

6. Sears W, Sears M. The attachment parenting book: a commonsense guide to understanding and nurturing your baby. Boston: Little Brown and Company, 2001:1-192.

7. Warren SL, Huston L, Egeland B, Sroufe LA. Child and adolescent anxiety disorders and early attachment. J Am Acad Child Adolesc 
Psychiatry 1997;36:637-44.

8. van IJzendoorn MH. Adult attachment representations, parental responsiveness, and infant attachment: a meta-analysis on the predictive validity of the Adult Attachment Interview. Psychol Bull 1995;117:387403.

9. Bartholomew K, Horowitz LM. Attachment styles among young adults: a test of a four-category model. J Pers Soc Psychol 1991;61:226-44.

10. Sroufe LA. Attachment and development: a prospective, longitudinal study from birth to adulthood. Attach Hum Dev 2005;7:349-67.

11. Fonagy P, Leigh T, Steele M, Steele H, Kennedy R, Mattoon G, et al. The relation of attachment status, psychiatric classification, and response to psychotherapy. J Consult Clin Psychol 1996;64:22-31.

12. Ma K. Attachment theory in adult psychiatry. Part 1: Conceptualisations, measurement and clinical research findings. Adv Psychiatr Treat 2006;12:440-9.

13. Jang MJ. Intergeneration transmission of attachment: mother's internal working model of relationships and infant attachment pattern [dissertation]. Seoul: Kyung Hee University, 1998:1-138.

14. Jung HS. The relationships among maternal attachment, caring behavior and children's attachment [dissertation]. Seoul: Sookmyung Women's University, 2000:1-73.

15. Yoo HI, Kim BN, Shin MS, Cho SC, Hong KE. Parental attachment and its impact on the development of psychiatric manifestations in schoolaged children. Psychopathology 2006;39:165-74.

16. Munafo MR, Yalcin B, Willis-Owen SA, Flint J. Association of the dopamine D4 receptor (DRD4) gene and approach-related personality traits: meta-analysis and new data. Biol Psychiatry 2008;63:197-206.
17. Thomas A, Chess S. An approach to the study of sources of individual differences in child behavior. J Clin Exp Psychopathol 1957;18:347-57.

18. Thomas A, Chess S. Temperament and development. New York: Brunner/Mazel, 1977:1-270.

19. Rothbart MK, Bates JE. Temperament. In: Damon W, Lerner N, editors. Social, emotional, and personality development. 6th ed. New York: Wiley, 2006:99-166. (Eisenberg N, editor. Handbook of child psychology; vol. 3).

20. Kagan J, Fox NA. Biology, culture, and temperamental biases. In: Damon W, Lerner N, editors. Social, emotional, and personality development. 6th ed. New York: Wiley, 2006:167-255. (Eisenberg N, editor. Handbook of child psychology; vol. 3)

21. Baumrind D. Current patterns of parental authority. Dev Psychol 1971; 4(1 Pt 2):1-103.

22. Baumrind D. Rearing competent children. In: Damon W, editor. Child development today and tomorrow. San Francisco: Jossey-Bass, 1989:34978.

23. Seifer R, Schiller M. The role of parenting sensitivity, infant temperament, and dyadic interaction in attachment theory and assessment. Monogr Soc Res Child Dev 1995;60:146-74.

24. Goossens FA, van IJzendoorn MH. Quality of infants' attachments to professional caregivers: relation to infant-parent attachment and day-care characteristics. Child Dev 1990;61:832-7.

25. Fonagy P, Steele M, Steele H, Moran GS, Higgitt AC. The capacity for understanding mental states: the reflective self in parent and child and its significance for security of attachment. Infant Ment Health J 1991;12:20118. 